NASA Technical Memorandum 4115

\title{
Vibration Testing \\ of Impact-Damaged \\ Composite Laminates
}

Joseph E. Grady and Erwin H. Meyn

Lewis Research Center

Cleveland, Obio

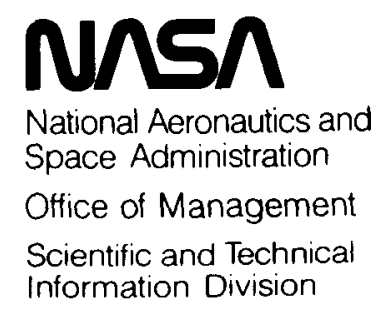




\section{Summary}

A new test is described that can be used to measure changes in the vibration properties of impact-damaged composite materials. Impact-induced delamination was observed to significantly affect natural frequencies of vibration and damping properties in cross-ply graphite/epoxy laminates. Natural frequencies are shown to drop by as much as half of their original value, and modal damping ratios can increase by a factor of up to eight when large amounts of damage are present. A simple finite-element model of the damaged impact specimens was used to predict the effect of delamination on certain vibration properties. A comparison of the finite-element calculations with the experimental measurements suggests that delamination was the dominant mechanism of flexural stiffness loss resulting from the transverse impact.

\section{Introduction}

Efficient use of advanced composite materials requires that in-service structural components be able to retain their structural integrity even if they contain internal flaws or defects of some nominal size. In composite materials, such flaws can result from fatigue, periodic overloading, or even impact during normal use; or they can be inadvertently introduced during the fabrication process. Localized impact damage usually occurs because of high local stresses near the point of contact with the projectile. However, as shown in figure 1, high transverse shear stresses near the midplane of a symmetric cross-ply laminate can cause additional matrix cracking in regions remote from the impact point (fig. 1(a)). When a matrix crack reaches a ply interface (fig. 1(b)), an interply delamination may form as the crack turns and propagates (fig. 1(c)) in the resin-rich region between plies. Such damage caused by transverse impact can be particularly degrading to a composite structure in terms of the losses in stiffness and strength that can occur. Interply delamination, in particular, can cause considerable loss in structural integrity.

The objective of the work presented herein was to nondestructively measure the change in mechanical properties caused by impact damage in a composite laminate. Since vibration properties of composites are critical in many aircraft applications, this report focuses on that area.

It would be reasonable to expect that the stiffness loss caused by structural damage would lead to a corresponding drop in the natural frequencies of that structure. Indeed, experiments (refs. 1 and 2) have confirmed this, and corresponding analytical approaches (refs. 2 and 3) have been developed to evaluate both the frequency and the damping properties in composite laminates having various forms of damage.

Because composite materials are relatively lightweight, a suitable vibration measurement technique must add a minimum of mass to the test specimen so as not to alter the very vibration properties being measured. This is particularly important for the small specimens used in the present experiments. This consideration rules out most accelerometers because of their mass. Strain gages would usually provide an excellent means of monitoring vibration because of their negligible weight and high signal resolution. In this case, however, conventional adhesive-mounted strain gages failed at the high impact velocities used in these tests. Therefore, a novel acoustic monitoring technique was devised that did not require that any instrumentation be mounted on the specimens. Instead, the vibration amplitude was monitored acoustically. A microphone and a sound-level meter were used to measure the acoustic intensity of the sound generated by the oscillating specimen. The resulting vibration-monitoring system is uniquely sensitive to small amounts of structural damage because the specimen itself remains unaltered by any external instrumentation.

A simple two-dimensional representation of the impactdamaged specimens was developed by using plane strain finite elements. In the finite-element model, a uniformly distributed "damage zone" was assumed to exist in the specimens after impact. The size of the damage zone varied with the incident kinetic energy of the impactor. A comparison of the calculated finite-element results with the natural frequencies measured after impact showed that the observed loss in flexural stiffness (caused by the impact damage) was due almost entirely to delamination. 


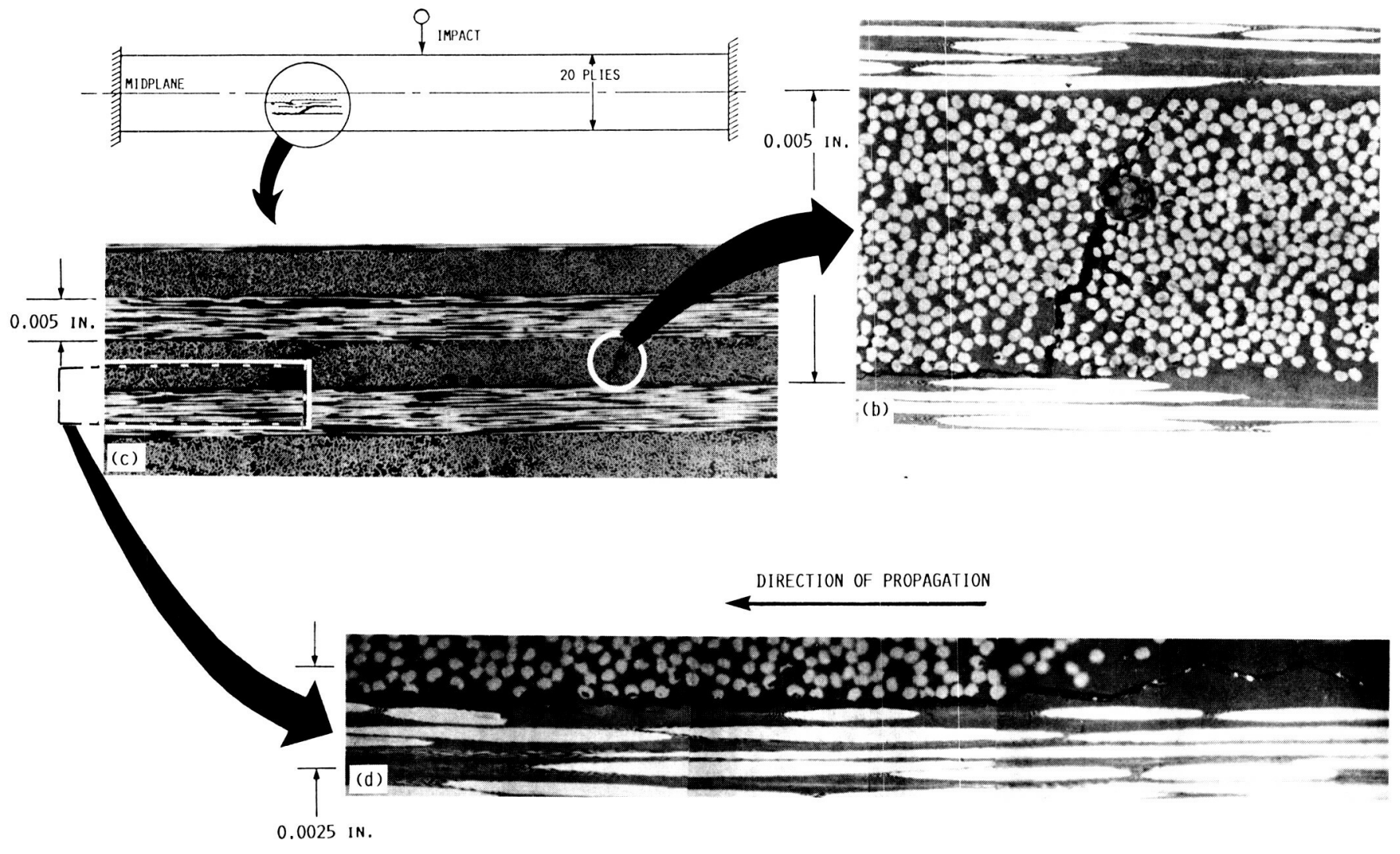

(a) Location of impact damage

(b) Damage initiates as transverse crack nears specimen midplane

(c) Delamination forms when transverse crack reaches $0^{\circ} / 90^{\circ}$ interface

(d) Delamination propagates along $0^{\circ} / 90^{\circ}$ interface.

Figure 1.-Impact-damage sequence in a $0^{\circ} / 90^{\circ}$ cross-ply laminate.

\section{Specimen Preparation}

A series of T300/934 graphite/epoxy test specimens were fabricated as shown in figure 2 . The 20-ply-thick specimens were laid up in a $[0 / 90]_{5 \text { s }}$ cross-ply configuration with simulated 1.0 -in. ${ }^{2}$ through-the-width delaminations embedded in them during the fabrication process. The delamination was introduced by inserting a 1-mil-thick Teflon strip between the two $90^{\circ}$ plies on either side of the specimen midplane prior to curing. The Teflon effectively prevented the plies from bonding together over the inch-long region and created a uniform "starter" delamination along the specimen midplane. The artificial delaminations created by this technique have been shown (ref. 4) to accurately simulate delaminations occurring naturally in composite structures during in-service loading.

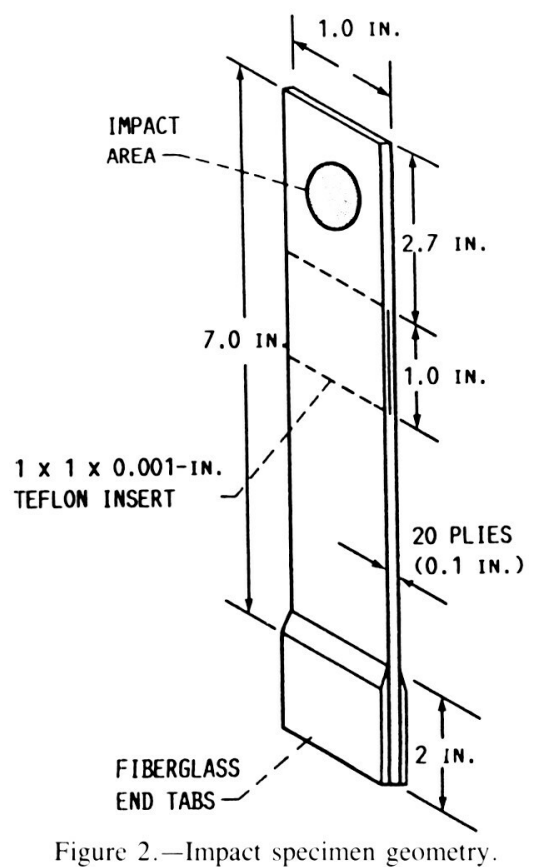

Figure 2.-Impact specimen geometry. 


\section{Vibration Testing: Apparatus and Procedure}

A series of vibration tests were performed on each of the impact specimens, prior to impact, so that their vibration characteristics could be determined in the undamaged state. Harmonic excitation of the specimens was applied through the magnetic field generated by a stationary solenoid driven by a waveform generator (fig. 3). The excitation force was applied through a small magnet of negligible mass that was glued to the free end of the cantilevered specimens. The amplifier boosted the output of the waveform generator, providing a magnetic field strong enough to vibrate the specimen. The waveform generator was programmed to vary the excitation frequency continuously within specified ranges, which included the first three resonant frequencies of the specimens. A sound-level meter and a microphone, placed underneath the cantilevered specimen (fig. 3), were used to monitor the magnitude of the resulting vibration acoustically. The increased sound level generated by the vibrating specimen was clearly audible near the resonant frequencies. The voltage level output by the sound-level meter varied in direct proportion to the amount of sound generated by the vibration. The voltage output was displayed in the frequency domain on the spectrum analyzer and in the time domain on the oscilloscope. Resonant frequencies were therefore indicated on the spectrum analyzer by peaks in the frequency response and on the oscilloscope by an increased magnitude of the sinusoidal output.

A spectrum analyzer display from the scan of a typical undamaged specimen at $0-$ to $10-\mathrm{kHz}$ excitation frequency is shown in figure 4 . The different resonances were clearly indicated by peaks in the display of output magnitude versus excitation frequency. In addition to the natural frequencies, the associated modal damping ratios can be determined by using one of several techniques. The half-power bandwidth

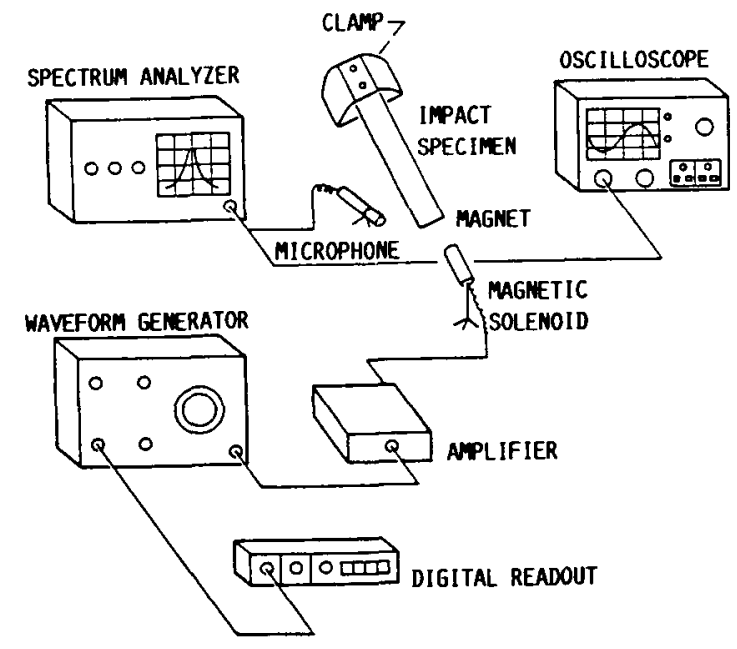

Figure 3.-Vibration test apparatus.

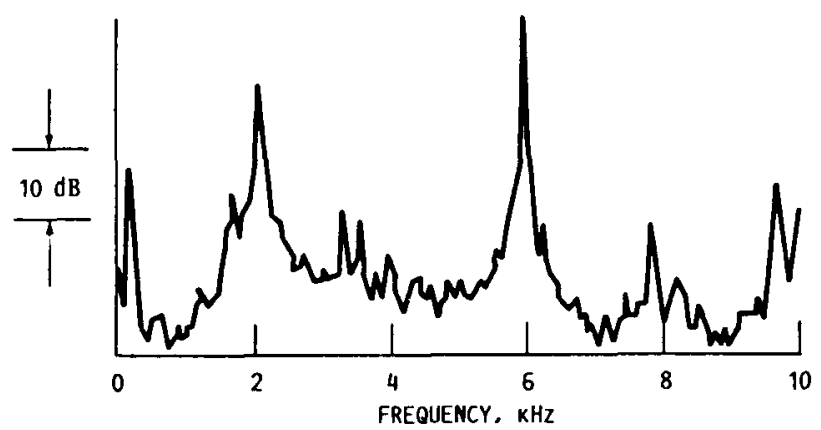

Figure 4.-Frequency response of undamaged specimen.

method (ref. 5) can be used to estimate effective damping properties if the width of the frequency response peak near resonance can be measured. This was the technique used.

\section{Impact Testing}

After the initial vibration tests of the undamaged laminates were completed, ballistic impact testing was performed to evaluate the damage tolerance capability of the cross-ply specimens. With the experimental setup shown in figure 5 , 1 -g rubber balls were fired at the cantilevered specimens. Progressively greater amounts of delamination crack extension were measured as the impact velocity was increased. The extent of impact-induced extension of the original embedded delamination was determined by visual inspection and measurement of the postimpact crack length along the edge of the specimen.

In addition, the damaged specimens were inspected ultrasonically through use of the C-scan technique (ref. 6), as shown in figure 6 . Here, the $\mathrm{C}$-scans indicated that, when a significant amount of crack extension occurred (figs. 6(b) and (c)), the variation of crack length across the specimen width was generally small. Therefore, external measurement of the crack length along the specimen edge should provide an accurate

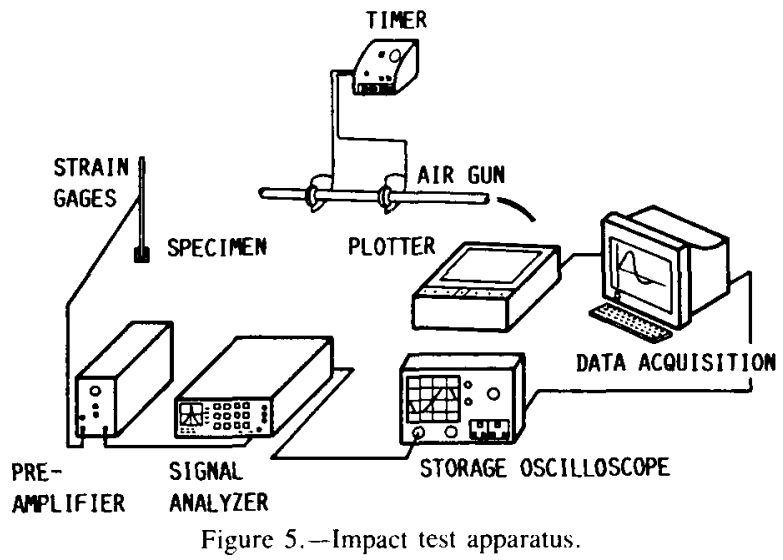



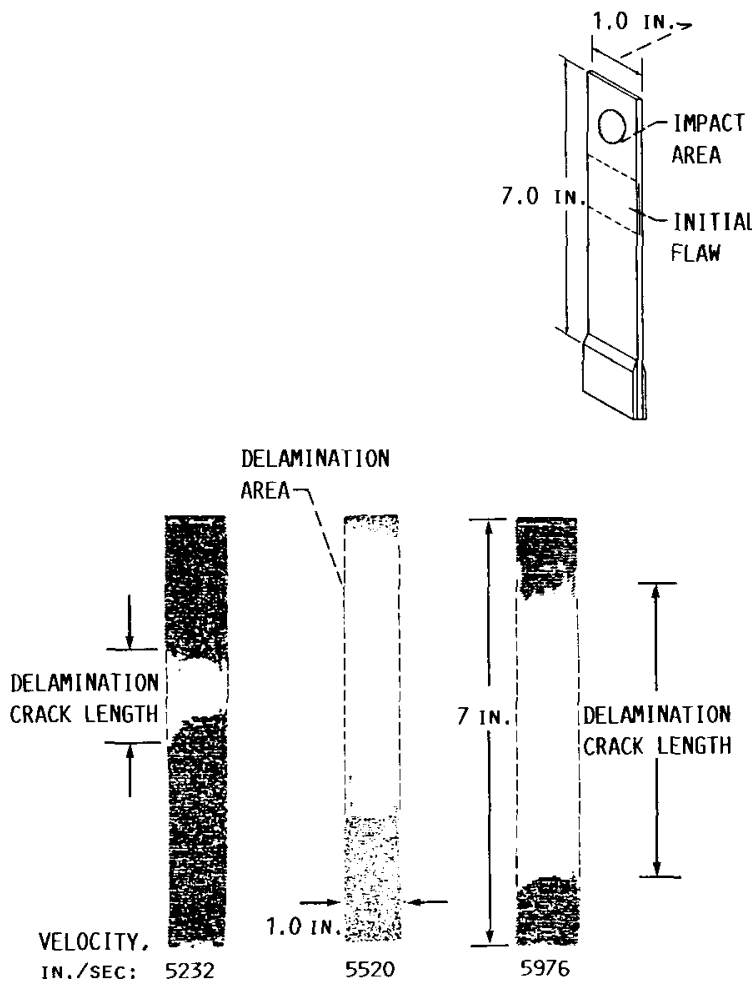

Figure 6.--Ultrasonic C-scans of impacted laminates.

estimate of the total delaminated area. So that the length of the delaminations after impact could be measured visually, a thin coating of bright yellow spray paint was applied to the edges of the specimens. This effectively served as a "brittle coating" that readily fractured as the delamination propagated underneath. The variation of delamination crack length with the kinetic energy of the impactor is shown in figure 7. The threshold energy level, above which crack extension occurred, is plainly visible in the figure. Allowing for some scatter in the data, the amount of delamination crack extension that occurs seems (ref. 7) to vary linearly with the impact energy.

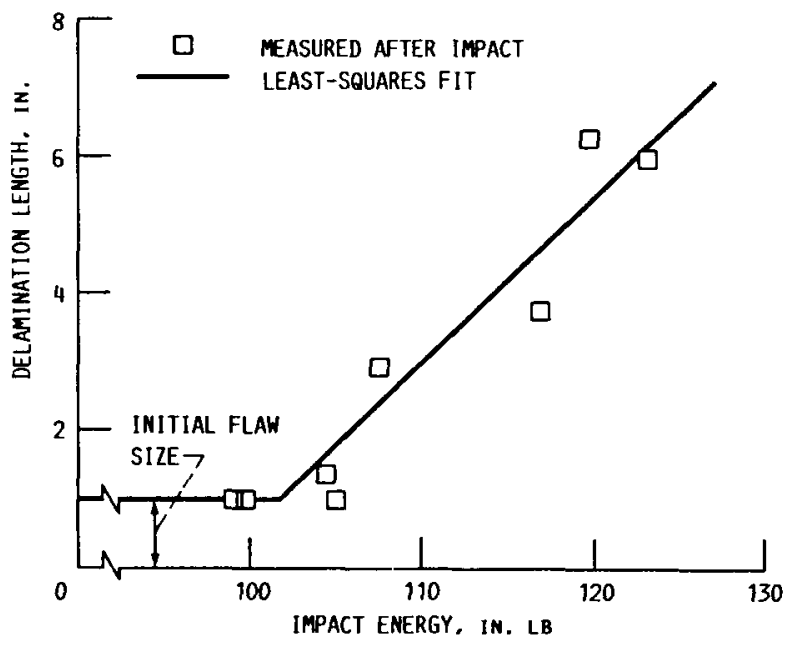

Figure 7.-Effect of impact energy on delamination crack length.

\section{Results and Discussion}

After the postimpact crack length in each specimen was measured as previously described, the specimens were again vibration tested. The effect of the impact-induced delamination on the first three flexural natural frequencies is shown in figure 8 and table $I$. The first two modes (figs. $8(\mathrm{a})$ and $8(\mathrm{~b})$ ) were relatively unaffected by small amounts of delamination but became progressively more sensitive at the longer crack lengths. The third mode (fig. 8(c)) showed greater sensitivity to damage for all crack lengths. This trend is in agreement with the observation in reference 1 that the natural frequencies of the higher modes are generally more sensitive to damage than are the lower frequencies.

Impact damage will also, in general, affect the damping properties of a structure. In this case, the primary mechanism causing this to occur is probably the increased frictional damping generated by the vibrating crack surfaces coming in contact with each other. Increased impact damage (delamination crack length) provides more surface area for the neighboring crack faces to contact, which in turn damps out the vibration
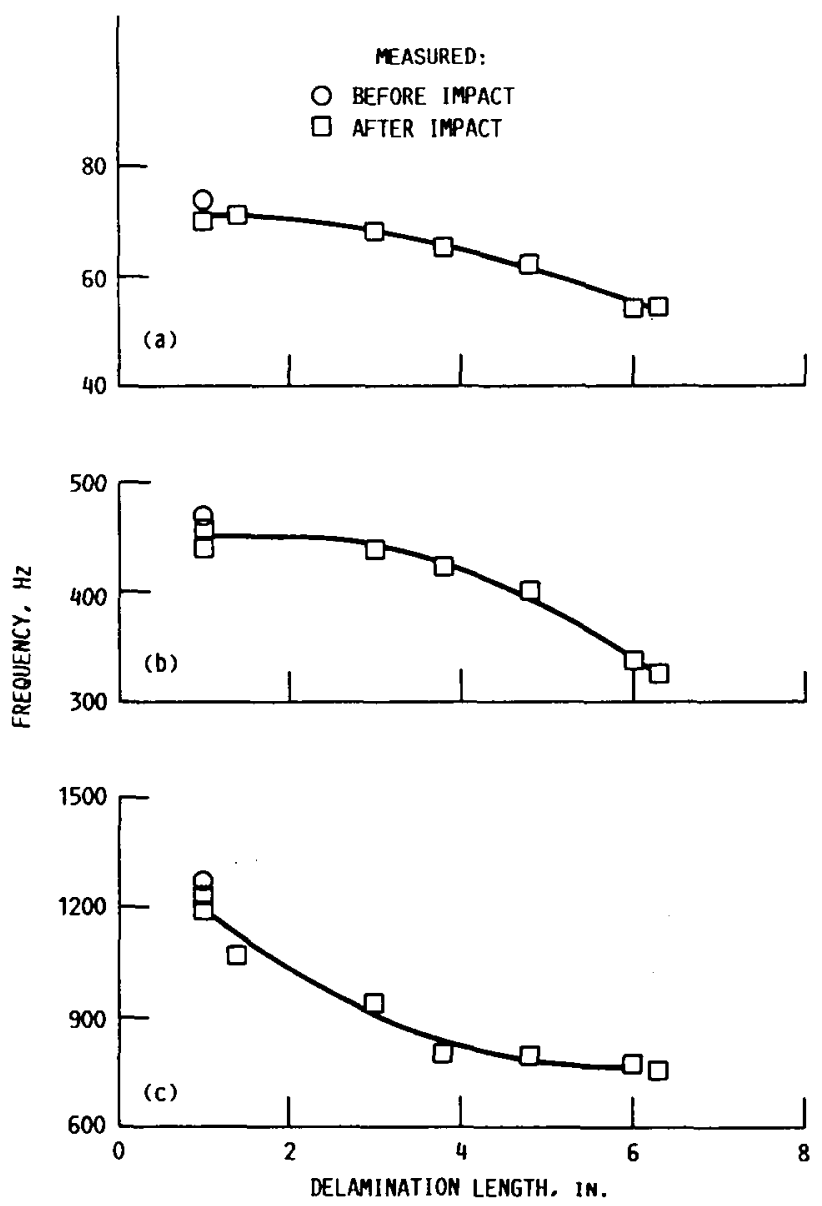

(a) Mode 1.

(b) Mode 2

(c) Mode 3 .

Figure 8.-Effect of delamination on natural frequencies. 
TABLE I.-MEASURED NATURAL FREQUENCY DATA FOR FIGURE 8

\begin{tabular}{|c|c|c|c|c|c|c|c|c|}
\hline Specimen & \multirow{2}{*}{$\begin{array}{c}\text { Impact } \\
\text { velocity, } \\
\text { in./sec }\end{array}$} & $\begin{array}{c}\text { Delamination } \\
\text { length } \\
\text { after impact, } \\
\text { in. }\end{array}$ & \multicolumn{2}{|c|}{$\begin{array}{c}\text { Mode 1, } \\
\mathrm{Hz}\end{array}$} & \multicolumn{2}{c|}{$\begin{array}{c}\text { Mode 2, } \\
\mathrm{Hz}\end{array}$} & \multicolumn{2}{c|}{$\begin{array}{c}\text { Mode 3, } \\
\mathrm{Hz}\end{array}$} \\
\cline { 5 - 9 } & & Before & After & Before & After & Before & After \\
\hline A1 & 5676 & 1.00 & 73 & 72 & 466 & 455 & 1265 & 1238 \\
A2 & 5820 & 1.00 & 74 & 70 & 468 & 437 & 1274 & 1186 \\
A3 & 5808 & 1.37 & 75 & 71 & 471 & 459 & 1277 & 1063 \\
A4 & 5892 & 2.95 & 72 & 68 & 452 & 437 & 1224 & 939 \\
A5 & 6144 & 3.77 & 73 & 65 & 458 & 422 & 1247 & 799 \\
A6 & 5784 & 4.83 & 73 & 62 & 460 & 399 & 1253 & 794 \\
A7 & 6300 & 6.01 & 70 & 54 & 449 & 335 & 1218 & (a) \\
A8 & 6216 & 6.29 & 73 & 54 & 461 & 324 & 1255 & 757 \\
\hline
\end{tabular}

${ }^{3}$ No data available

more effectively. The measured results for the first three flexural vibration frequencies are shown in figure 9 and table II. As observed earlier, some modes, such as the second mode (fig. 9(b)) in this case, are more sensitive to the damage than others, with the fundamental mode (fig. 9(a)) being the least sensitive. These trends in the damping behavior are strikingly similar to those reported in reference 1 , in which a different vibration monitoring technique was used and a carefully controlled series of artificial delaminations of varying size were introduced into unidirectional glass/epoxy specimens.

The similarity between the data shown here and those of reference 1 is further evidence that artificially generated delaminations can have the same structural effect on the composite laminate that naturally occurring delaminations (such as those generated by impact) would have. Since each of the vibration modes has its own associated deformation shape ("mode" shape), these results further suggest that the shifts that occur in both damping and resonant frequencies depend not only on the extent of the damage but also on the location of the damage within the structure.

The damaged specimens were modeled with two-dimensional plane strain elements. A uniform delamination crack length was assumed to exist through the specimen width, this being consistent with observations made earlier in the discussion of figure 6 . The damaged condition of the specimens was modeled numerically by deleting finite elements along the midplane of the model in the area corresponding to the measured delamination crack length, as shown in figure 10 . This procedure simplified the computational evaluation of the effect on vibration properties of a variable-length delamination. More complete numerical modeling details are given in reference 7 .

For simplicity, other damage modes that were undoubtedly present to some extent, such as matrix and fiber cracking, were not accounted for in the computational simulation. The good comparisons between the numerical and measured results shown in figure 11 and table III seem to suggest, however, that delamination was the dominant mechanism of flexural stiffness loss in these tests. Figure 10 also shows that, for all
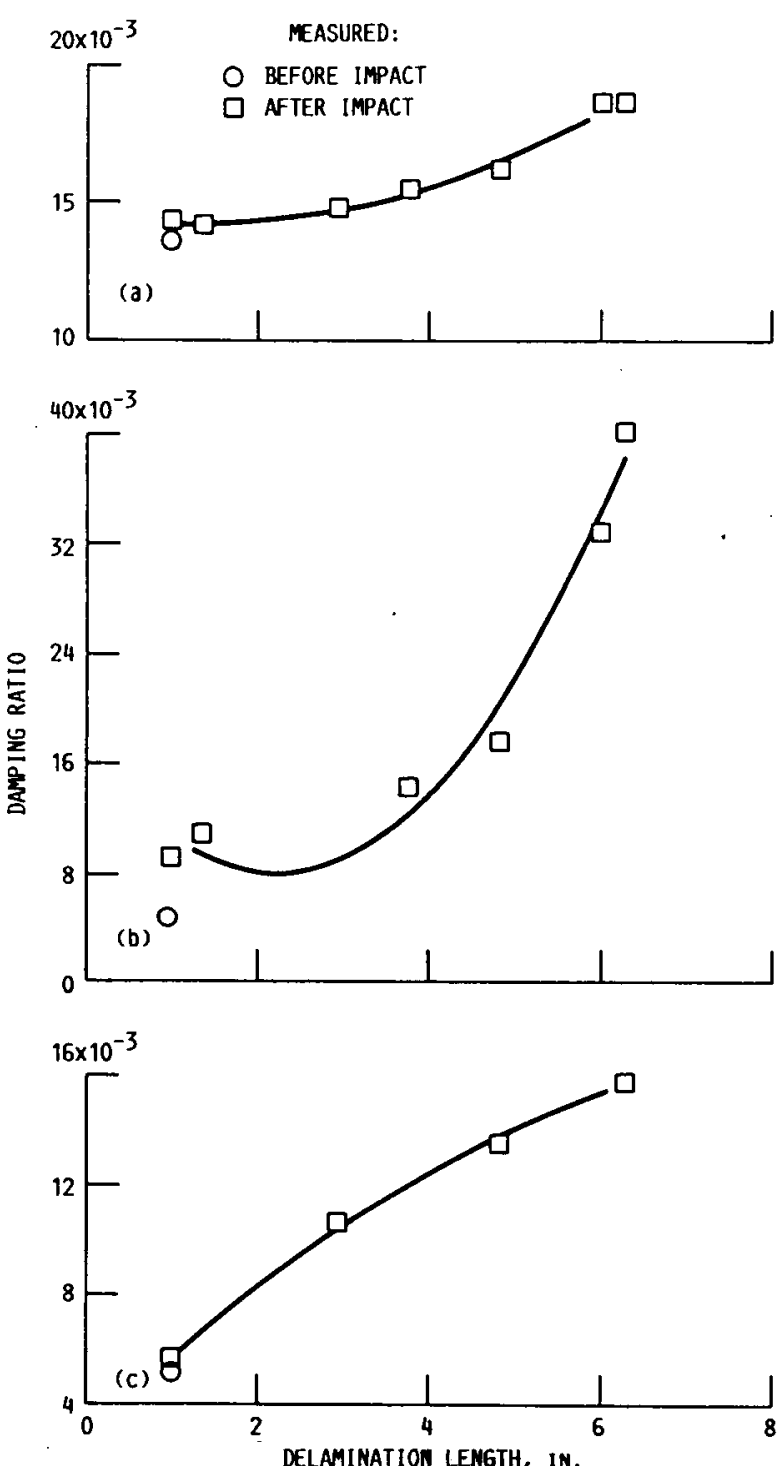

(a) Mode 1

(b) Mode 2 .

(c) Mode 3 .

Figure 9.-Effect of delamination on damping ratios. 
TABLE II.-MEASURED DAMPING COEFFICIENT DATA FOR FIGURE 9

\begin{tabular}{|c|c|c|c|c|c|c|c|c|}
\hline \multirow[t]{2}{*}{ Specimen } & \multirow{2}{*}{$\begin{array}{l}\text { Impact } \\
\text { velocity, } \\
\text { in./sec }\end{array}$} & \multirow{2}{*}{$\begin{array}{l}\text { Delamination } \\
\text { length after } \\
\text { impact, } \\
\text { in. }\end{array}$} & \multicolumn{2}{|c|}{ Mode 1} & \multicolumn{2}{|c|}{ Mode 2} & \multicolumn{2}{|c|}{ Mode 3} \\
\hline & & & Before & After & Before & After & Before & After \\
\hline $\mathrm{A} 1$ & 5676 & 1.00 & $13.7 \times 10^{-3}$ & $13.9 \times 10^{-3}$ & $6.41 \times 10^{-3}$ & $9.15 \times 10^{-3}$ & $3.95 \times 10^{-3}$ & $5.65 \times 10^{-3}$ \\
\hline $\mathrm{A} 2$ & 5820 & 1.00 & 13.5 & 14.3 & (a) & (a) & (a) & (a) \\
\hline A3 & 5808 & 1.37 & 13.3 & 14.1 & 6.37 & 10.9 & (a) & (a) \\
\hline A4 & 5892 & 2.95 & 13.9 & 14.7 & (a) & (a) & 5.72 & 10.7 \\
\hline A5 & 6144 & 3.77 & 13.7 & 15.4 & 2.18 & 14.2 & (a) & (a) \\
\hline A6 & 5784 & 4.83 & 13.7 & 16.1 & 4.35 & 17.5 & 5.59 & 13.5 \\
\hline A7 & 6300 & 6.01 & 14.3 & 18.5 & 6.68 & 32.8 & (a) & (a) \\
\hline A8 & 6216 & 6.29 & 13.7 & 18.5 & 2.17 & 40.1 & 7.97 & 15.9 \\
\hline
\end{tabular}

${ }^{a}$ No data available.
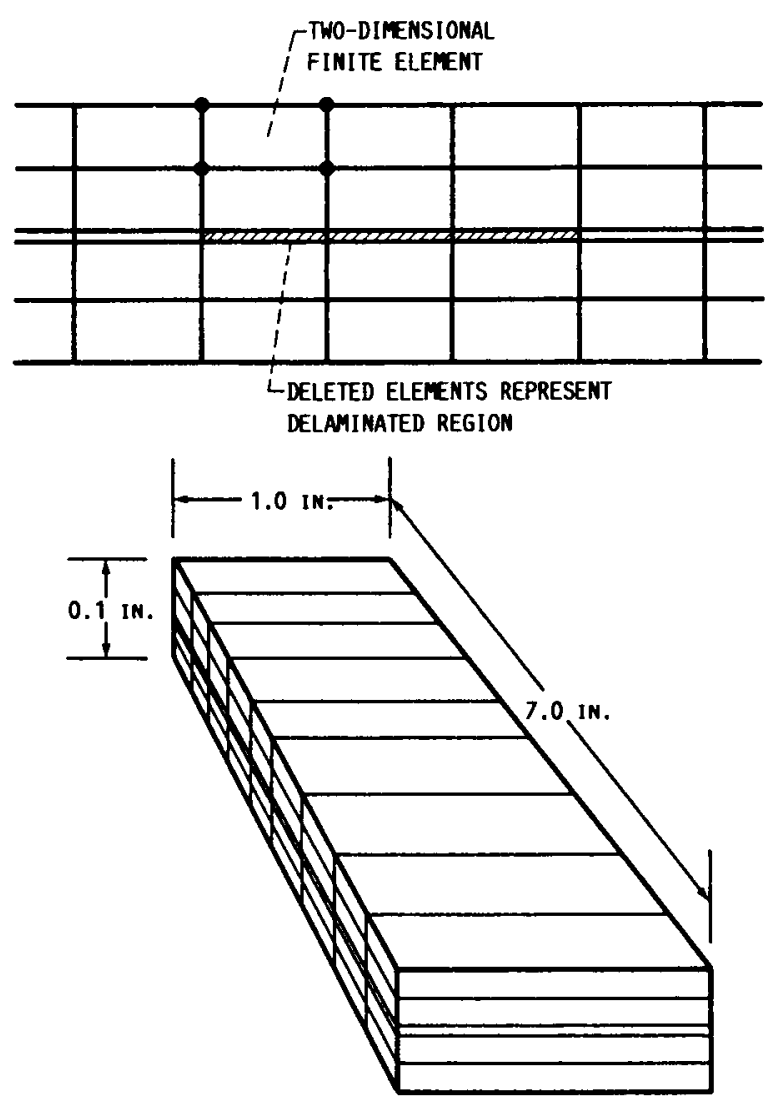

Figure 10.-Finite-element idealization of delamination damage along specimen midplane.

delamination sizes, the measured drop in frequency was somewhat higher than that calculated in the corresponding finite-element analysis. This drop in frequency was due in part to the additional damage, other than delamination, existing in the impacted specimens. This additional damage resulted in
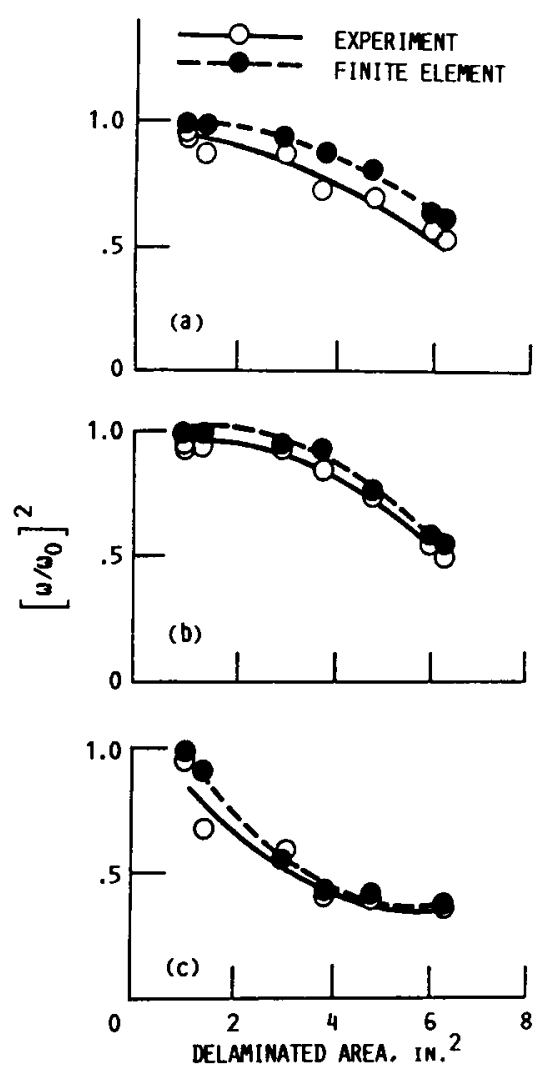
(a) Mode 1 .
(b) Mode 2 .
(c) Mode 3 .

Figure 11.-Dependence of natural frequencies on damaged areia

a further stiffness loss and a corresponding further drop in natural frequencies. Because this additional damage was not included in the finite-element model of the impacted specimens, its effect is not shown in the calculated results. 
TABLE III.-FINITE-ELEMENT CALCULATIONS FOR FIGURE 11

\begin{tabular}{|c|r|r|r|}
\hline $\begin{array}{c}\text { Delamination } \\
\text { length, } \\
\text { in. }\end{array}$ & \multicolumn{3}{|c|}{$\begin{array}{c}\text { Natural frequency, } \\
H z\end{array}$} \\
\cline { 2 - 4 } & $\omega_{1}$ & $\omega_{2}$ & $\omega_{3}$ \\
\hline & 69 & 430 & 1188 \\
1.0 & 69 & 430 & 1140 \\
1.37 & 67 & 422 & 891 \\
2.95 & 65 & 418 & 784 \\
3.77 & 63 & 379 & 772 \\
4.83 & 56 & 331 & 748 \\
6.01 & 55 & 319 & 737 \\
6.29 & &
\end{tabular}

\section{Conclusions}

Vibration testing is an effective means of nondestructively measuring the effect of impact damage on the mechanical properties of composite materials. A new vibration test technique was presented that does not require that instrumentation be mounted on the test specimen, thereby minimizing the measurement error that can be introduced by mass loading. Comparisons of the measured drop in natural frequencies caused by impact damage with the results of a simple finite-element analysis suggest that delamination was the mechanism through which most of the loss in flexural stiffness occurred. Damping properties were also altered by the impact damage. Damping ratios for the first three flexural vibration modes were shown to increase significantly as the amount of impact-induced delamination area increased.

Lewis Research Center

National Aeronautics and Space Administration

Cleveland, Ohio, February 17, 1989

\section{References}

1. Lee, B.T.; Sun, C.T.: and Liu, D.: An Assessment of Damping Measurement in the Evaluation of Integrity of Composite Beams. J. Reinforced Plastics Composites, vol. 6, Apr. 1987, pp. 114-125.

2. Ju, F.D.; and Mimovich, M.E.: Experimental Diagnosis of Fracture Damage in Structures by the Modal Frequency Method. J. Vibration Acoustics Stress Reliability Design, vol. 110, no. 4, Oct. 1988, pp. 456-463.

3. Allen, D.H.: Harris, C.E.; and Highsmith, A.L.: Prediction and Experimental Observation of Damage Dependant Damping in Laminated Composite Beams. The Role of Damping in Vibration and Noise Control. L. Rogers and J.C. Simonis, eds., ASME, 1987, pp. 253-263.

4. Sierakowski, R.L.: Ross, C.A.; and Malvern, L.E.: Studies on the Fracture Mechanisms in Partially Penetrated Filament Reinforced Laminated Plates. ARO-15987.7-U.S. Army Research Office, 1981 (Avail, NTIS, AD-A110741).

5. Paz, M.: Structural Dynamics. Van-Nostrand Reinhold Co., 1980.

6. Vary, A.: Ultrasonic Nondestructive Evaluation, Microstructure, and Mechanical Property Interrelations. NASA TM-86876, 1984.

7. Grady, J.E.; and Sun, C.T.: Dynamic Delamination Crack Propagation in a Graphite/Epoxy Laminate. Composite Materials: Fatigue and Fracture, H.T. Hahn, ed., ASTM STP-907, 1986, pp. 5-31. 


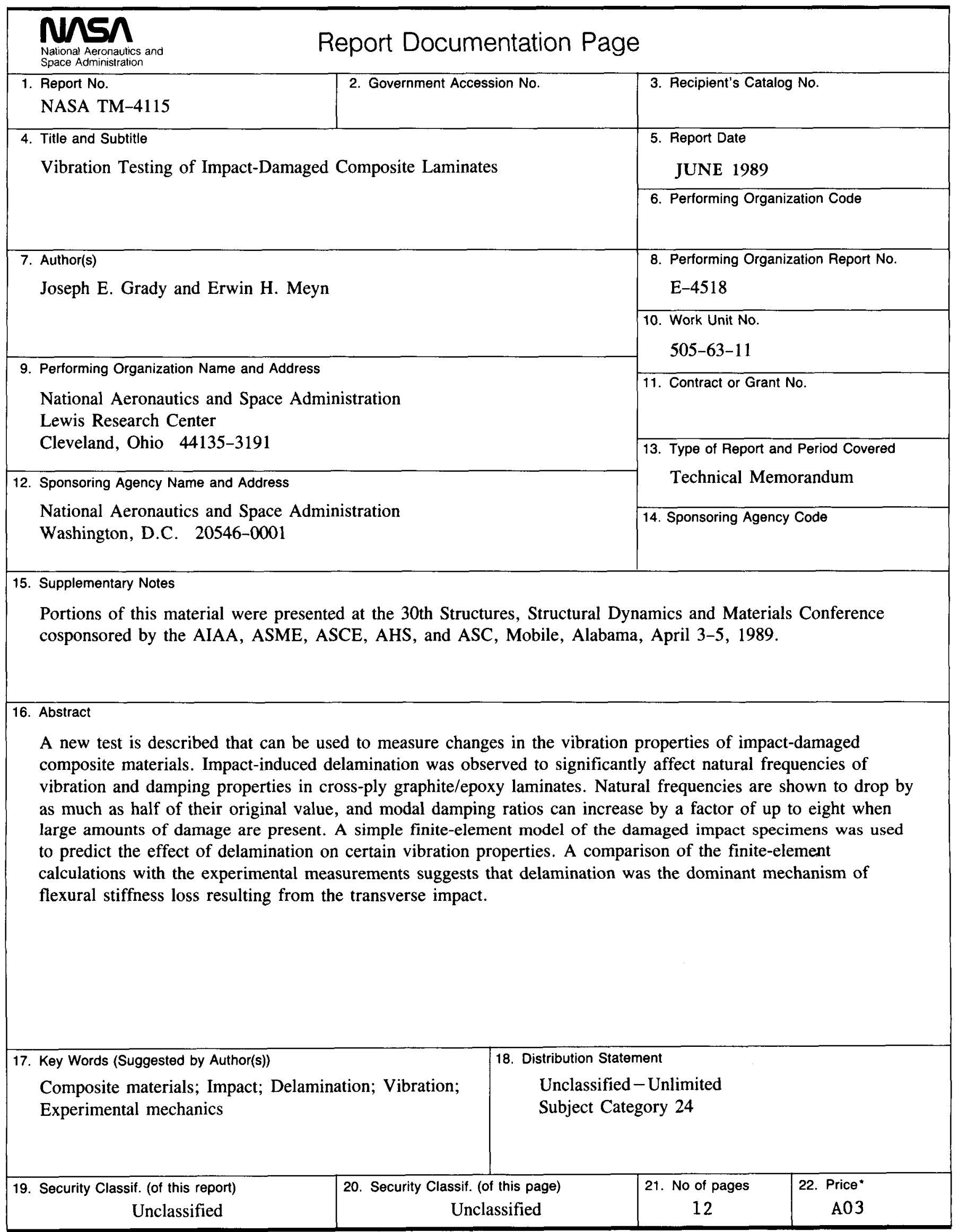

